\title{
DESIGN AND FINITE ELEMENT ANALYSIS OF AN EIGHT WHEEL STAIR CLIMBING CART
}

\author{
MD ZAHID Hasan ${ }^{1}$, MOSHIUR Rashid ${ }^{2}$ \\ ${ }^{I}$ Faculty of Mechanical Engineering, Rajshahi University of Engineering \& Technology, Department of \\ Industrial \& Production Engineering, Rajshahi-6204, Bangladesh, email: zahidipe13@ gmail.com \\ ${ }^{2}$ Faculty of Mechanical Engineering, Rajshahi University of Engineering \& Technology, Department of \\ Mechanical Engineering, Rajshahi-6204, Bangladesh
}

\begin{abstract}
Most of the people living in developing or less developed countries have limited earning to provide somehow their basic needs and usual staff. Carrying goods is a regular task in life and several products have been invented to minimize efforts in this purpose. However, the price and features of most available products are out of the reach for the people of limited earnings. Stair climbing cart is very useful for those houses where a lift is not available. In this research, a modified mechanical design with eight wheels providing pause-rest feature has been represented with the equations of pulling force, constraints of stair dimensions and climbing mechanism. The 'House of Quality Diagram '(QFD)' has been added to accomplish the vision of further market research and customer satisfaction. The factor of safety and different types of stress have been determined for different types of loads and conditions. In addition, the details of the material with dimension, design and feasibility analysis have led this research to uniqueness.
\end{abstract}

KEYWORDS: Stair Climbing, Pause-rest feature, Mechanics, Simulation, QFD, FEA.

\section{Introduction}

Cost is a primary factor in business which helps to compete with competitors providing customer satisfaction [1]. But if the product cannot meet the customer's needs, they will not buy it at all even at the lowest price. Products are designed for a target customer group according to their buying capability, lifestyle, purpose of use, physical capability, etc. Before designing a product, existing features \& price of competitors including their customers buying capability is very efficient $\&$ effective to determine a new customer group who are not served by the competitors [2]. This research represents the design of the stair climbing cart with new innovative features. The main structure on which the load would be carried has been designed with fewer materials than the existing's. In order to increase the stability of the cart 4 wheels mechanism has been used. With the help of lower 2 wheels which will be in touch with the ground, the cart with load can be balanced. This feature will reduce stress while pulling goods on stairs. A very high tensile strength is needed to carry loads on stairs. The reduced weight of the design will significantly reduce the tensile stress during pulling upward the cart. Also, compressive stress will be reduced during pulling downward. A better gripping system has been provided considering ergonomically factors of the customers. The tensile-compressive stress when pulling \& gripping is two major human factors in the design of this stair climbing cart [3]. Only fewer types of joints have been used in this design so that the difficulty of manufacturing minimizes. Only one type of welded joints increased the simplicity \& sustainability of the cart.

The mechanical design modification has increased the feasibility of the cart both economical $\&$ qualitative perspective. Moreover, the new mechanism with the pause-rest feature will definitely satisfy the customer because of lower force exertion requirement. Finally, the quality 
function deployment (QFD) of the stair climbing cart has been prepared considering the target customer requirements. People of lower earnings are the main targeted customers of this modified design. The quality function deployment represents all customer specifications and engineering specifications with the relationship among all types of the feature as a house of quality of this product. The finite element analysis on the handle and load-carrying part has helped to determine the safe load for carrying to ensure the longevity and sustainability of the product that resulted in higher load-carrying capability.

\section{Literature Review}

A lot of Patents have been found on Stair Climbing Cart. But none considered the cost minimization or design for less earning customers. Most of the patents focused on ease of loadcarrying over the stairs, mechanism, structure, wheel design, etc. A brief analysis of the previous patents has been added so that the uniqueness of this new design can be easily identified.

(Charles J. Fouchey, 1981) patented a Hand truck assembly with unique wheels to climb up $\&$ down the stairs with braking mechanism \& also provided a locking mechanism for locking the wheel assemblies in a set position [4]. (John F Fleming, 1969) invented power assisted stairclimbing vehicle or dolly for use in transporting heavy objects and the like up and down stairs or traversing Surfaces having abrupt changes in elevation [5]. (Eshcol S Gross, 1970) patented a stair climber dolly where the one-way clutch bearing permitting forward rotation of the groups of wheels about said axis but prevent reverse rotation of said wheels [6]. (Chiun J. Cheng, 1989) patented such a stairways accessible cart where two main wheels \& two auxiliary wheels were foldable and the auxiliary wheels were spring-loaded by two-way hinges [7]. (Robert H. Shaffer, 1977) patented an im-proved cart capable of being readily collapsed for storage and having front wheel means and a pair of spaced stair-climbing assemblies to move up or down a flight of stairs [8]. (Henry Diener, 1985) patented a cart that includes large wheels for movement over rough terrain while the cart is loaded and a set of smaller wheels for movement of the cart within buildings. The cart also includes a stair climbing apparatus to enable pulling a loaded cart up a flight of stairs [9]. (Roman Andruchiw, 1978) patented a stair-climbing device using reversible electric motor \& load bearing shoes pivotally connected with load-bearing shoes. The device can move forward \& backward with pivotally connected arms \& sensing head at the contact of the threads [10]. (Ed Carlile, 1989) patented a hand-propelled cart which includes a separable wheeled frame having a different collapsible section to carry different types of goods [11]. (Chenette Edmond Zenan; Joseph C Chenette, 1952) patented 'Endless Tread Stair Climbing Truck' to lift heavy objects through stairs where front wheels are mounted with belts [12]. (John Grace, 1997) patented a collapsible, foldable cart, having a frame with spaced-apart first and second longitudinal frame members defining a plane, and a pair of wheels and a wheel axle connected to the frame [13]. (Eugene A. Kazmark, 1999) patented a collapsible cart includes a pivotable platform, a pivotable handle, and collapsible and adjustable tube assemblies for placing the cart in an extended or retracted position [14]. (William B. Martin, 1987) patented a unique stair climbing cart using only two wheels. "Each wheel is comprised of a plurality of lobes like teeth on a gear, each lobe has two surfaces which are symmetrical around a lobe centerline, with each surface being made up of a portion of an involute curve defined by a circle having a particular radius. The wheel may be made to specifications allowing exact fit on a particular size stairstep and a properly fitting wheel will move in a close approximation of a straight line parallel to the staircase incline as it moves up a flight of stairs" [15]. (Hans vom Braucke; Manfred vom Braucke, 1997) patented a col-lapsible hand trolley which has two wheels pivoted about a horizontal axis mounted at the lower end and foldingunfolding features also about a vertical axis [16]. (Hong, Seo, Kim, Kim, \& Kim, 2013) designed an optimum hand-carrying rocker-bogie mechanism for stair climbing [17]. (Eshcol 
Silas Gross, 1972) patented "STAIRWAY ACCESSIBLE CARRY CART WITH FOLDAWAY WHEELS" where he used auxiliary wheels on the lower portion of it telescopic arms for redistributing the loads on the stairs with two-way hinges, four springs \& four rods [18]. (Samuel Wyrick, 2007) patent-ed a cart which has three-wheel assemblies in both side that are designed to rotate when contact is made with stairs, thereby allowing the cart to climb the stairs [19]. (Zhang \& Xi, 2012) worked on the design optimization for the stair-climbing wheelchair [20]. (Ki-Soo Kim, 2013) designed a driving system for stair climbing vehicles where a power generation unit and a power transmission unit is installed with the frame. The power transmitted in the wheels so that the wheels can climb obstacles by rotating the driven units [21]. (Krys, Mostýn, \& Kot, 2014) designed a shaped wheel for stair climbing robots by the basic principles of shape analysis, simulations \& prototyping [22]. (Steve, Paul, Carson, David, \& Levins, 2015) patented an adjustable lift truck where exists a first end opposing a second end and the frame defines a longitudinal axis that extends from the first end to the second end. "Also, a pair of laterally spaced-apart out-riggers extend generally perpendicularly to the longitudinal axis of the frame" [23]. (Richard Danziger, 2015) patented a stair climbing assistance device which contains a first grip and a second grip on opposite sides of the central axis and each grip being connected to the other by first and second connecting members that combine with the first and second grips to form a handle frame [24]. (Cheng, 2018) patented such a stair climber where total of 8 small wheels has been used with ergonomically designed handles. The height can be adjusted to the product and there are two chambers for product housing [25]. (Behera \& Gupta, 2018) designed a stair climbing assisting wheelchair with two degrees of freedom legs containing four-bar parallel linkage and each leg is fitted with actuators [26]. (Paška, Z., Fojtík, F., \& Ferfecki, P. 2016) used photoelasticity methodology to find out the components of stress tensor in-plane specimens with the help of an algorithm in MATLAB program [27].

It is clear that in recent years no research has been published emphasizing the convenience of climbing through stairs. When stress will be reached higher upon hands during pulling the cart with loads through stairs especially when climbing up then pause would be required. This design has a new feature of four wheels with which the cart can be placed standing between two stairs which have been illustrated in figure 5. This research would be very helpful for any business group that wants to grab the opportunity to business with this product. Engineering and customer specifications with possible competitor analyses have been described for this design which has not been added in the previous designs. Also, this is the simplest design where the only welded joint has been used and the frame is a single part which has improved the reliability of the structure.

\section{$3 \quad$ Methodology and Design}

The mechanical design of the stair climbing cart has been developed considering available materials. Low-cost available materials help to reduce the cost of a product easily. Also, the availability of the technology of processing the materials is very important during the design of the product. Continuous material supply at the lowest cost has a great impact on product quality $\&$ cost [28]. The 3D view of the optimized final product is given in the figure 1 . In this design, the lowest number of structural members have been used as well as the lowest type of joints. There is no complex machining process to manufacture this mechanical design. Fewer machining processes \& ease of manufacture will help to reduce the cost a lot and increase reliability [29].

Only three types of structural members have been used in this model. The use of fasteners has also been reduced. Only nuts \& bolts are used as fasteners in this model. Assemble- 
disassemble time reduction and simplicity both have been achieved simultaneously. Fewer fasteners also help to increase product durability and longevity.

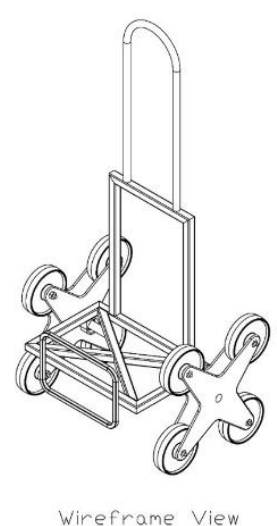

Fig. $13 \mathrm{D}$ view of the final product

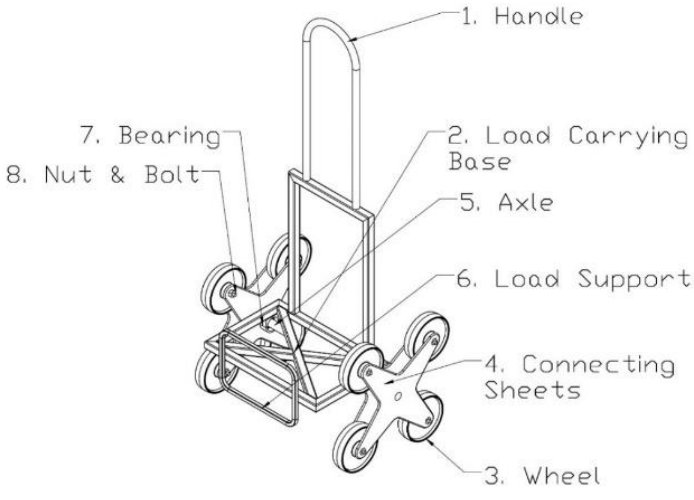

Fig. 2 Main Parts of the stair climbing cart

Four wheels can rotate along own axis and two wheel-connecting sheets have been used in both sides so that the assembly of four wheels can rotate about its own axis to climb stairs. The whole setup of wheels \& connecting sheets has been fastened with nuts \& bolts. A ball bearing has been used in each side at the contact zone of the mainframe $\&$ the axle to reduce friction. The main parts have been shown in figure 2.

The main load-carrying part is no. 2 as marked in the figure 2 . The object will be placed on it. The no. 6 part of which name is load support has been added to prevent the load from slipping backward. In case of carrying heavy loads, ropes can be used to tie the loads with the load support \& the frame under the handle. The dimensions of the stair-climbing cart are given below in figure 3.

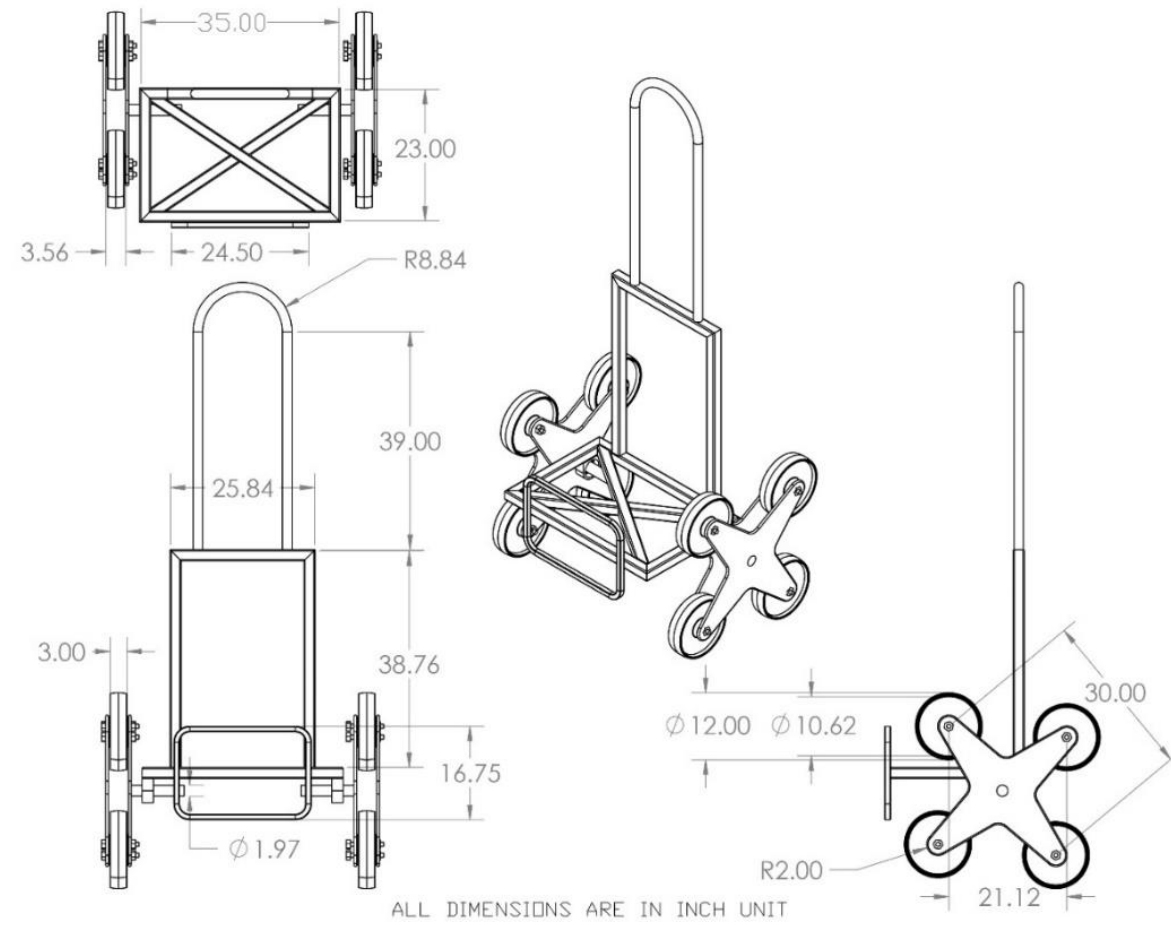

Fig. 3 Required dimensions of the stair climbing cart 
The anthropometric measurement concept for better gripping has been provided in the design of the handle. The total diameter of the handle is 1.68 inches (42.67 mm approximately) including gripping material. The gripping material is soft rubber which will reduce stress in fingers during carrying the cart by holding it in the handle [30].

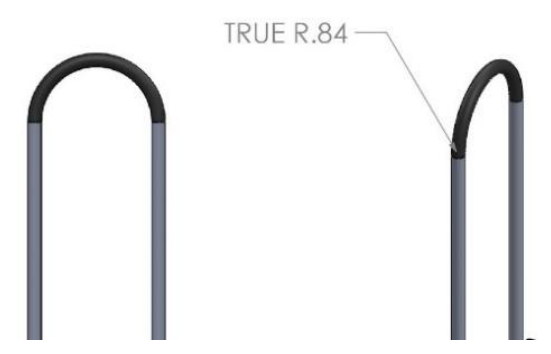

Fig. 4 Design of the Handle with a diameter

The unique feature of this design has been represented in figure 5. During pulling the load to upstairs tensile stress upon hand increases a lot. This may result in pain as well as fatigue while carrying loads. The four-wheel mechanism will enable the users to take a pause on the way for rest. The cart can stand on two stairs as illustrated in figure 5.

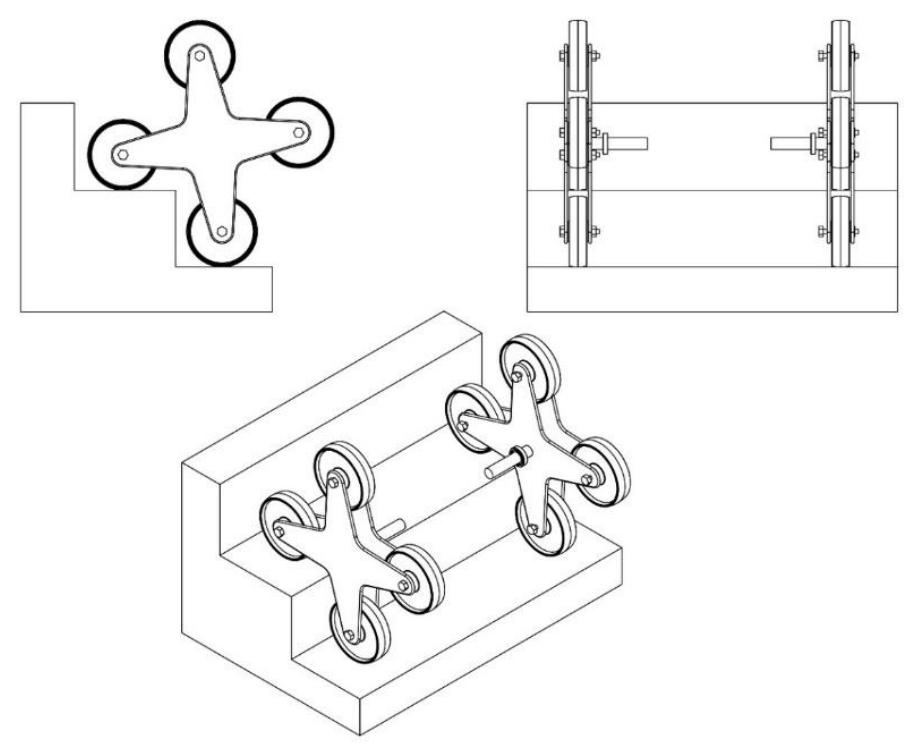

Fig. 5 Pause \& rest feature while climbing stairs

The operator will pull the load at the force $F$. The individual wheels will rotate at the torque $\mathrm{T}_{\mathrm{b}}$ \& the wheel assembly with the plates will rotate at the torque $\mathrm{T}_{\mathrm{a}}$ in order to climb the next stair. The climbing mechanism has been clearly illustrated in figure 6 . The operator can pause the cart in any stage of the climbing either on a single stair or occupying two stairs. The total assembly of the wheels will be rotated and climb the stairs when the wheel stacks with a vertical plane of the stair. The actual dimensions of the stairs have been ignored in the mechanisms. Because the mass of the stair climbing cart is constant, the pulling or pushing force will vary according to the load that will be carried on the cart. The pulling angle varies upon the height of the users that also changes the reaction force as well as pulling force. The friction may also be a factor in increasing the pulling force. The load should be bonded with the frame so that it cannot produce vibration on the frame. 


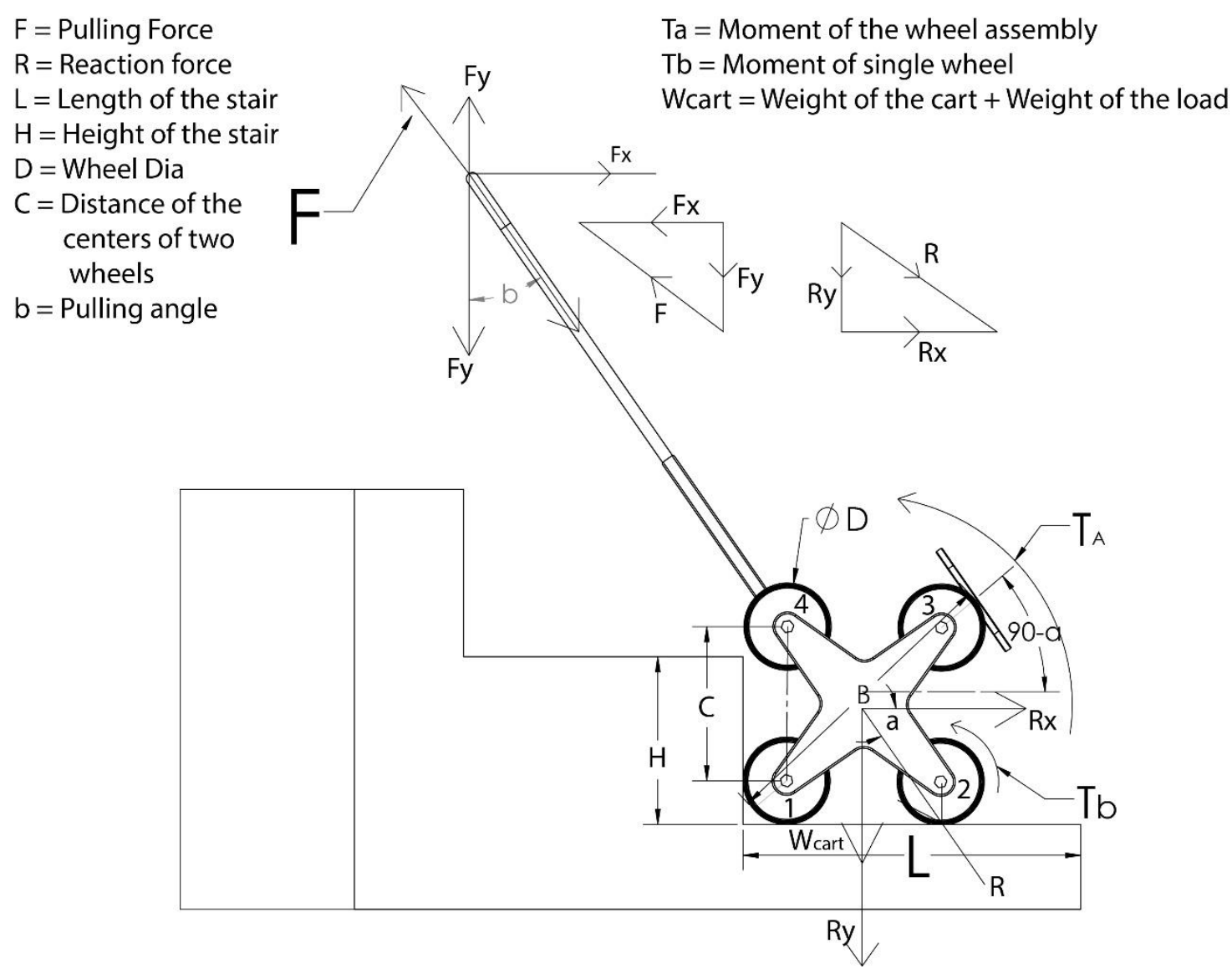

Fig. 6 Stair climbing mechanics with load

The angle between the handle and horizontal depends upon the height of the operator. Length of the stair $(\mathrm{L})$ \& height of the stair $(\mathrm{H})$ may vary in different countries or regions. Goods that users will carry on the stair climber will have to be tied with rope or another way so that cannot move or slide down. During the stair climbing, the friction between ground wheels \& stair allows them to rotate and proceed forward. When a wheel gets in contact (In figure 6, wheel 1) with a stair vertical plane $(\mathrm{H})$ then it becomes the center of rotation of the total wheel assembly. After rotation at a certain angle the top wheel (In figure 6, wheel 2) gets in contact of the stair horizontal plane and the center of the wheel becomes static for that moment and the full assembly rotates. Only the force $\mathrm{F}$ is required in order to pull the stair climber to the upward. In a reverse way, it can be pushed downward. Therefore, pushing slowly at the reverse direction of the same magnitude of $\mathrm{F}$ will be the best way for climbing down the stairs. Pulling may cause a higher amount of jerking. $W_{\text {cart }}=R_{y}$.

Pulling and Pushing force calculation formula:

$$
\begin{gathered}
\text { For upward climbing, the pulling force }|F| \geq R \\
\text { where, } R=\sqrt{R y^{2}+R x^{2}} \\
\text { Or, } R=R_{y} \cdot \cos b
\end{gathered}
$$

The stair climbing mechanism illustrated in figure 7 can help to understand the wheel position and rotation angle required to climb a stair with two rotation and a translation motion. 180-degree rotation is required to climb a stair. After 360 degrees rotation, the wheels return to the order stated in step 1 . The constraint for climbing stairs for this cart is:

$$
H \ngtr C
$$




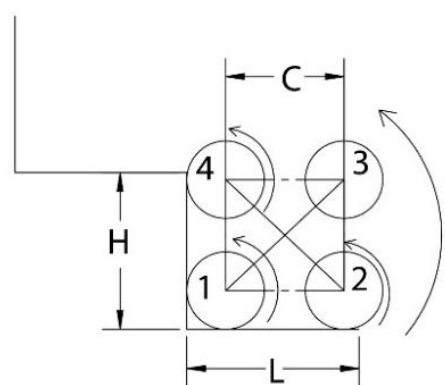

Step 1 (Traction of Wheels with stair)

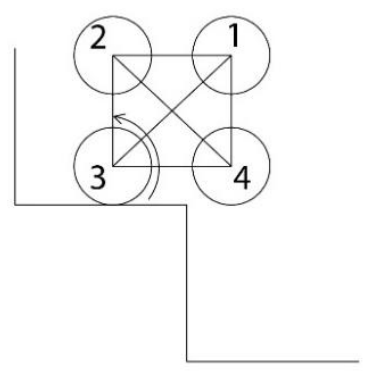

Step 2: Rotation

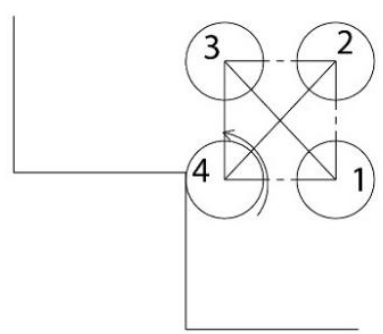

Step 3: Rotation

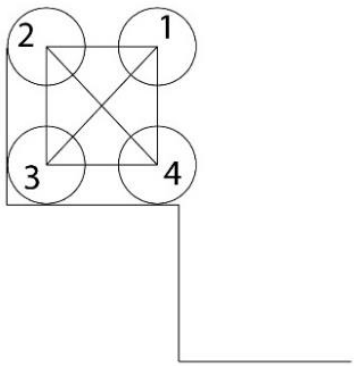

Step 4: Translation to the stair vertical face

Fig. 7 Stair climbing cycle with four wheels

The quality function deployment of this product will help the manufacturers to understand the co-relations among the engineering specifications and the customer requirements. All required customer requirements and engineering specifications have been tied into a co-relation and also two potential competitor analysis has been added in this QFD.

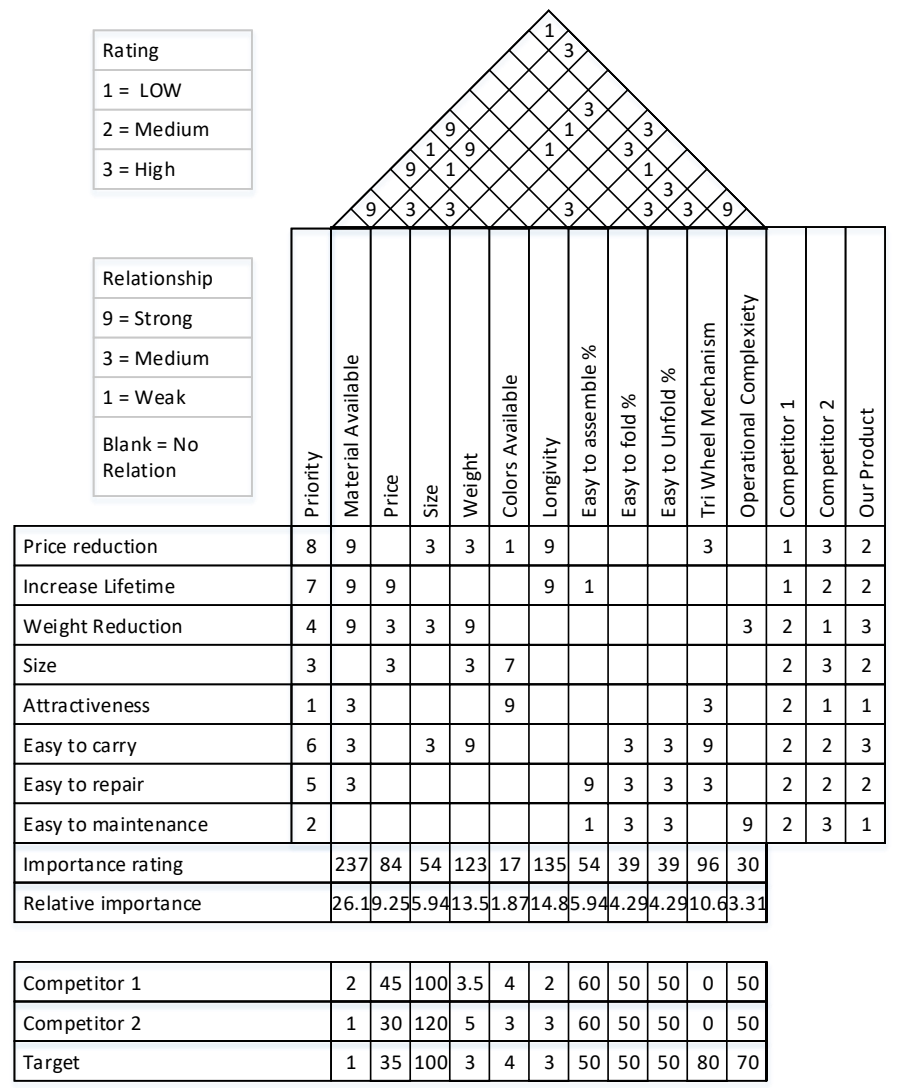

Fig. 8 The house of quality of the stair climbing cart 


\section{$4 \quad$ Finite Element Analysis with Results}

The tensile strength of the handle portion is very high. Simulation in ANSYS Workbench 17.0 was done applying different tensile loads on the handle. There is a very low probability of failure under heavy tensile load while carrying objects. Figure-9 represents the maximum shear stress simulation result when a $500 \mathrm{~N}$ tensile load is applied on the handle. This is a static simulation \& the lower portion of the structure is fixed. Different results in stress for different loads are given below for better understanding. The structure is highly sustainable in tensile load. The very high magnitude of the tensile load is required for failure. Usually, the tensile load will not be more than $3000 \mathrm{~N}$. Heavier objects and cumbersome in size \& shape just like beds, heavy furniture, etc. and these are not carried on stair climbing carts.

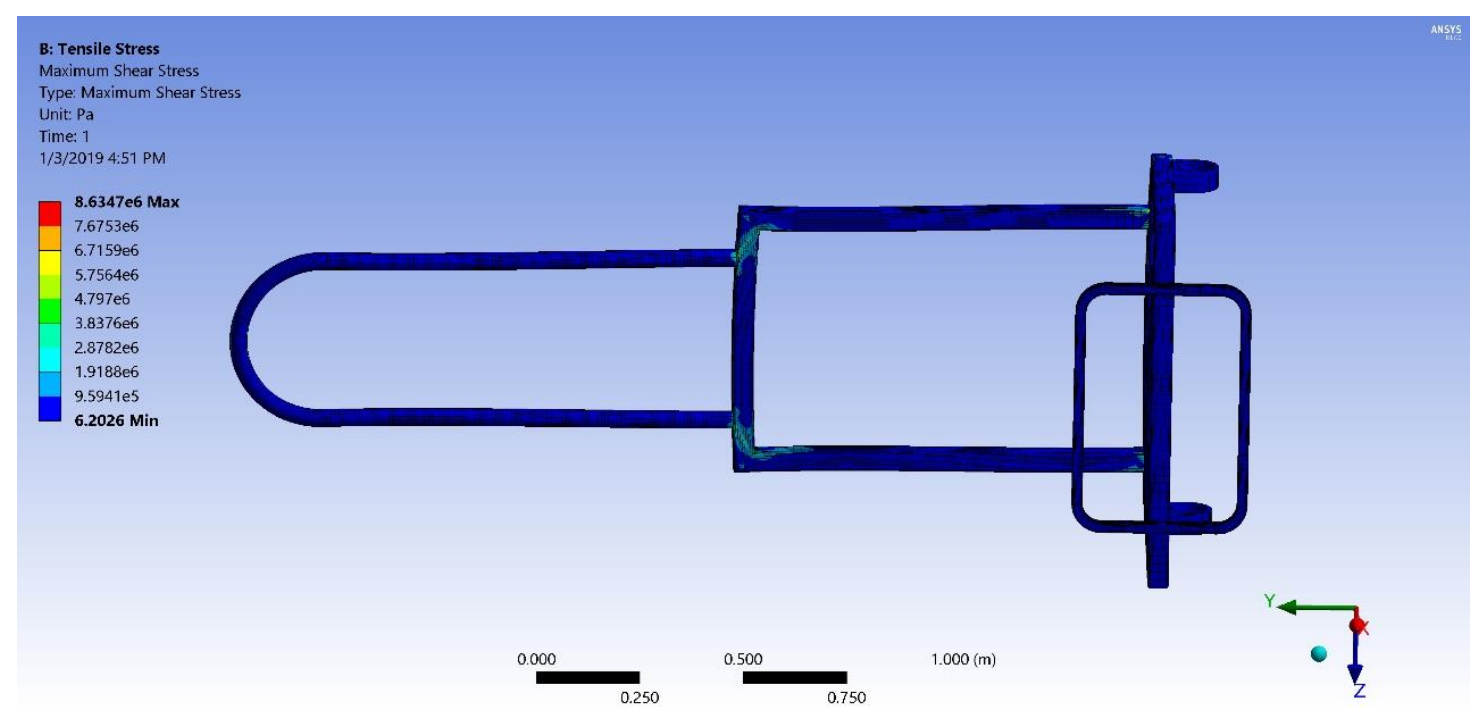

Fig. 9 Maximum shear stress under $500 \mathrm{~N}$ tensile load on the handle

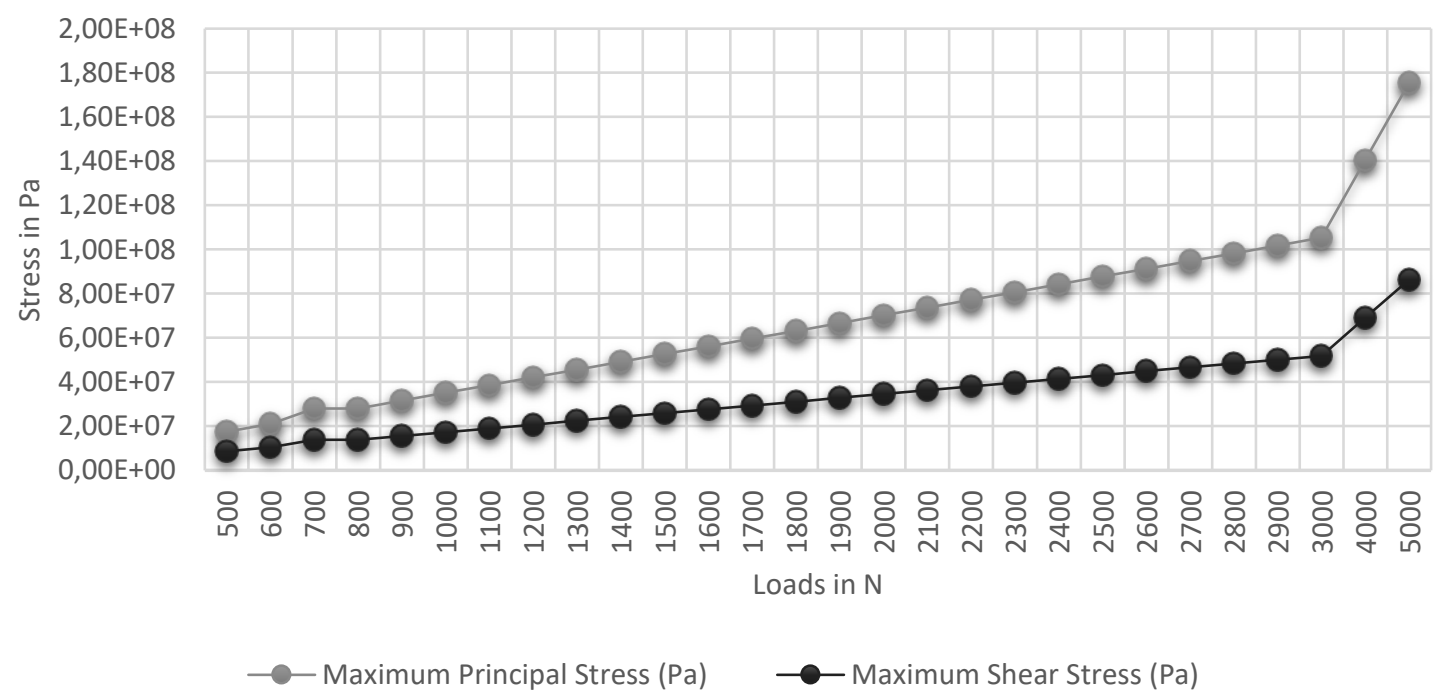

Fig. 10 Tensile Load vs Maximum principal and Maximum Shear stress plot

From figure 9-12 it is clearly seen that there is enough safety factor in the most vulnerable zones which are welded joints. $5000 \mathrm{~N}$ load is extremely high for stair climbing carts. Such heavy loads cannot be carried with the cart because the main frame cannot carry such a heavy load. In this way, welded joints have increased the sustainability, durability \& longevity in a significant amount. In the case of load-carrying (dynamic condition), the stress will be lower and the safety factor will be higher than static. Because in the static condition the lower portion 
was fixed and load has been exerted on the handle in the pulling direction. In the dynamic condition, the lower portion \& handle proceeds simultaneously in the same direction. So, the upper portion is more than enough feasible \& sustainable [31].

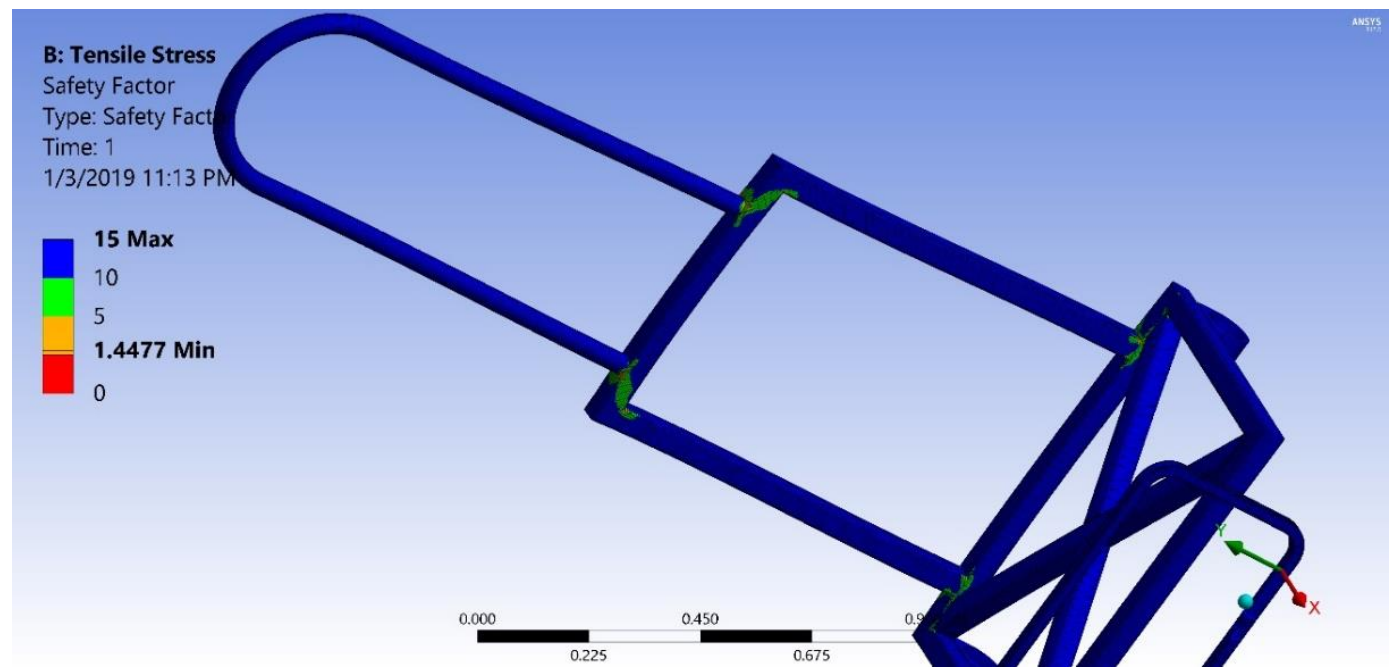

Fig. 11 The factor of Safety Distribution under 5000 N Tensile load

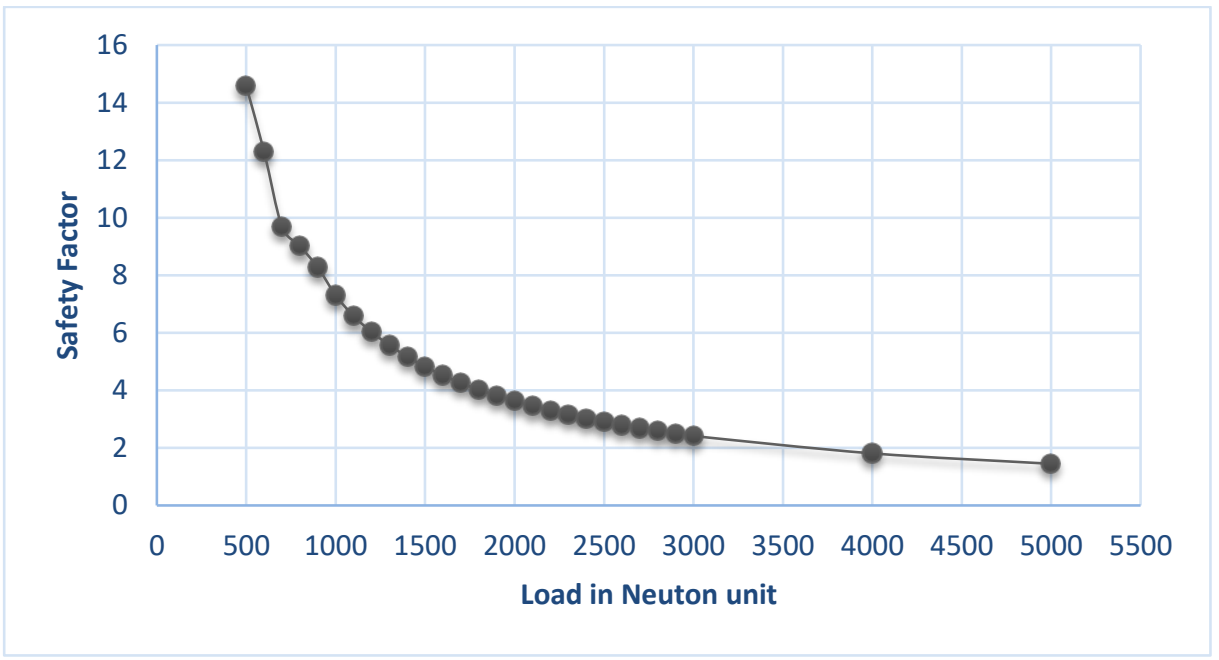

Fig. 12 The factor of safety for different tensile loads

In order to determine the safe load that can be carried with the cart, structural simulation has been performed in SolidWorks 2018.

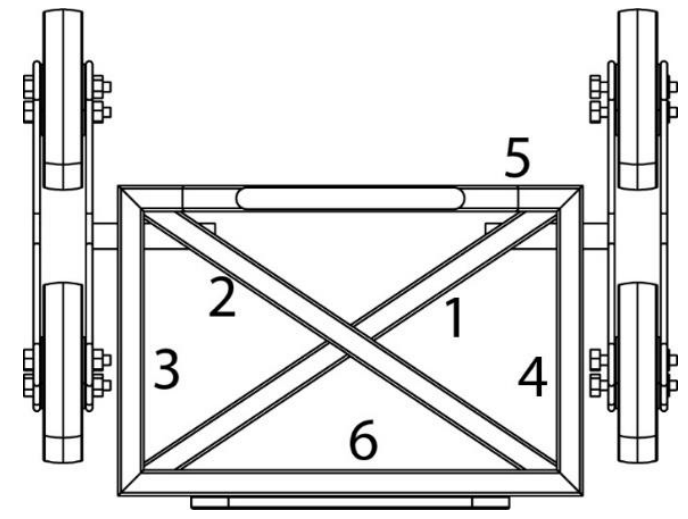

Fig. 13 Loads Applied on the 1 and 2 Face along $-Y$ direction 
Material Properties:

Elastic Modulus: 210000

$\mathrm{N} / \mathrm{mm}^{\wedge} 2$

Poisson's Ratio: $\quad 0.28$

Shear Modulus: $79000 \mathrm{~N} / \mathrm{mm}^{\wedge} 2$

Mass Density: $\quad 7800 \mathrm{~kg} / \mathrm{m}^{\wedge} 3$
Mesh Properties:

Elements: High Quality; Jacobian Points: 4

Mesh Type: Standard Mesh

Global Size: $7.67128747 \mathrm{~mm}$

Tolerance: $0.38356437 \mathrm{~mm}$
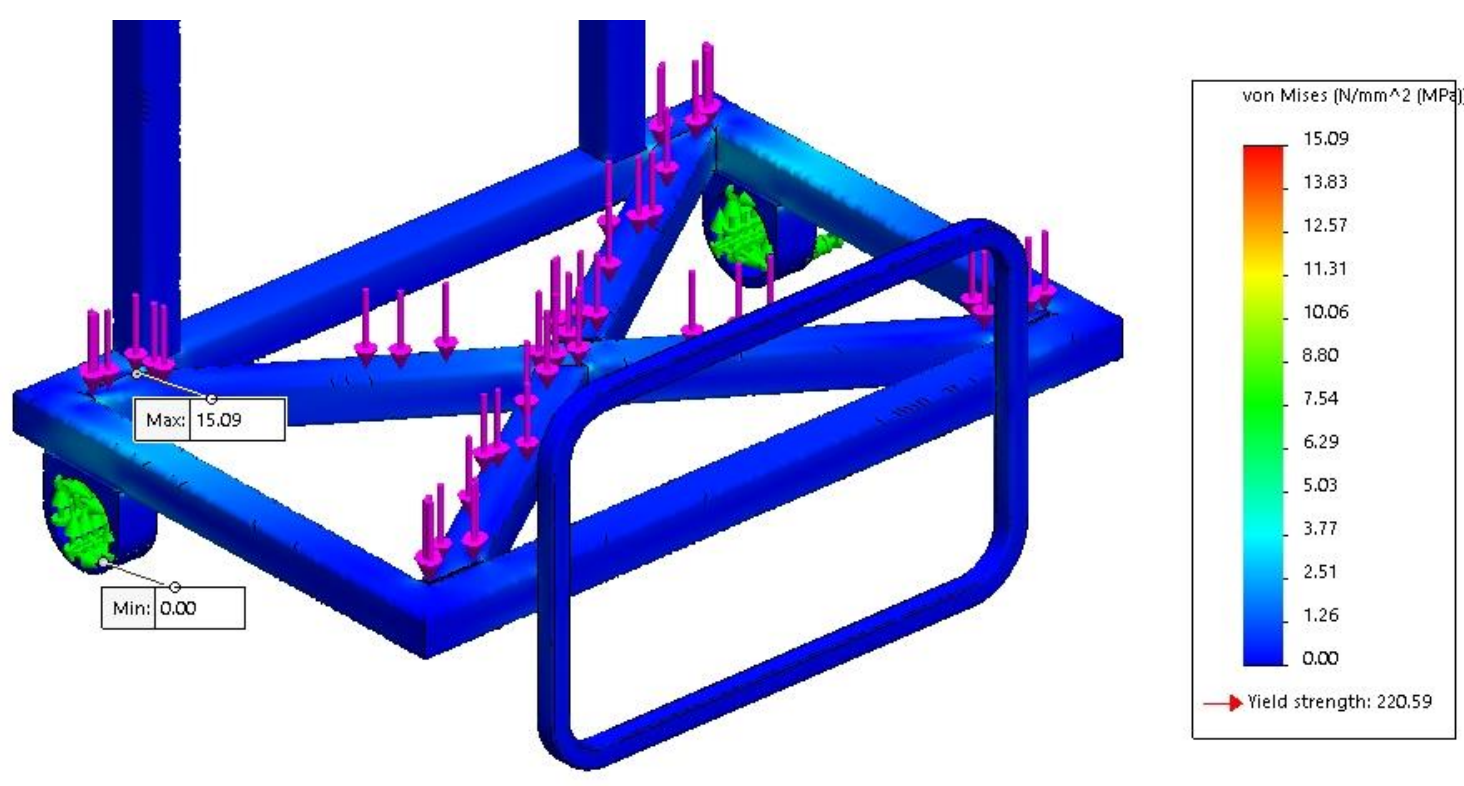

Fig. 14 Von-Mises stress distribution under 200 N static load

The green marked holes are fixed that will contain the support from the wheel shaft in total assembly. The static structural simulation was performed under a long-range of load in order to determine the safe load beyond that the cart will fail at some point in the structure. Nodal vonmises stress on various faces was also calculated.

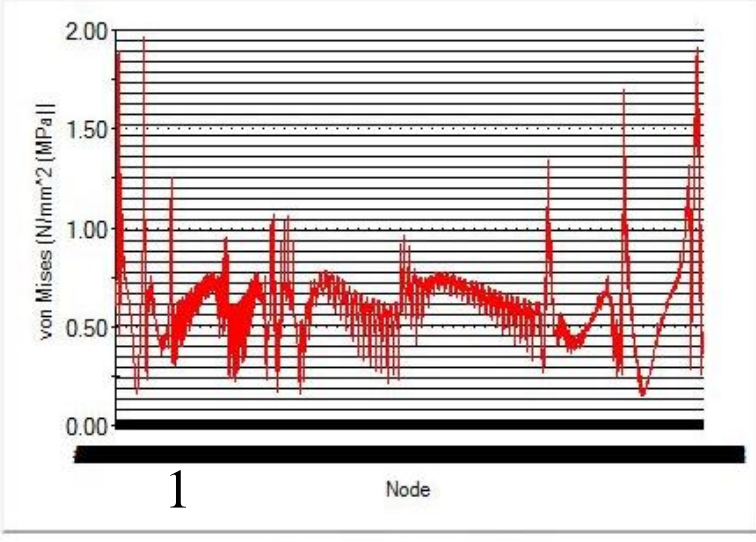

von Mises (N/mm^2 (MPa))

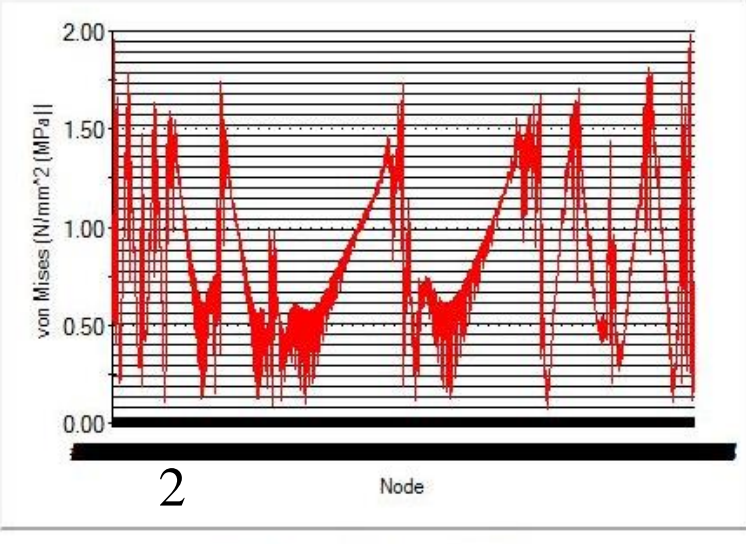

von Mises (N/mm 2 (MPa)) 

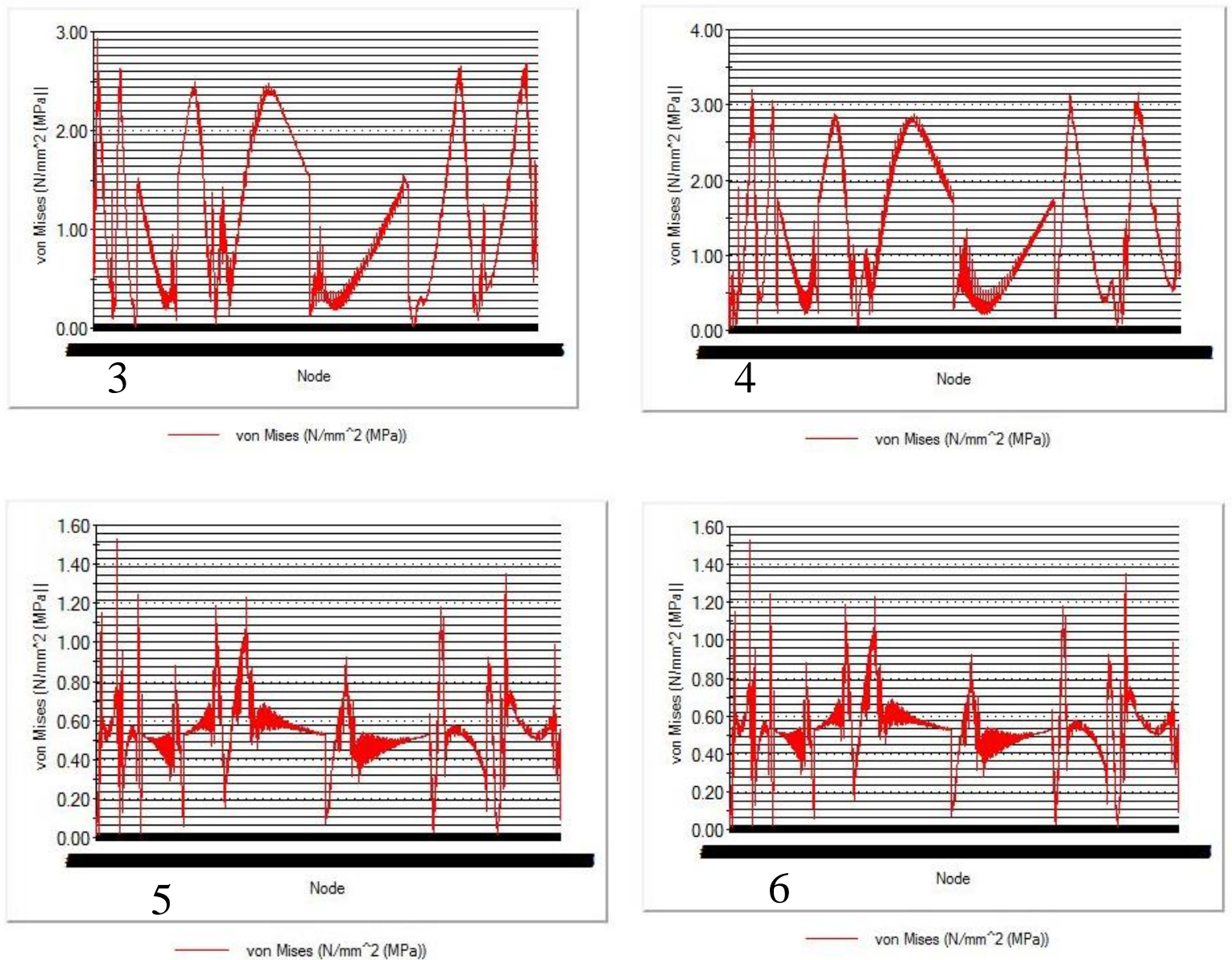

Fig. 15 Nodal Von-Mises stress on the faces 1-6 in order at $200 \mathrm{~N}$

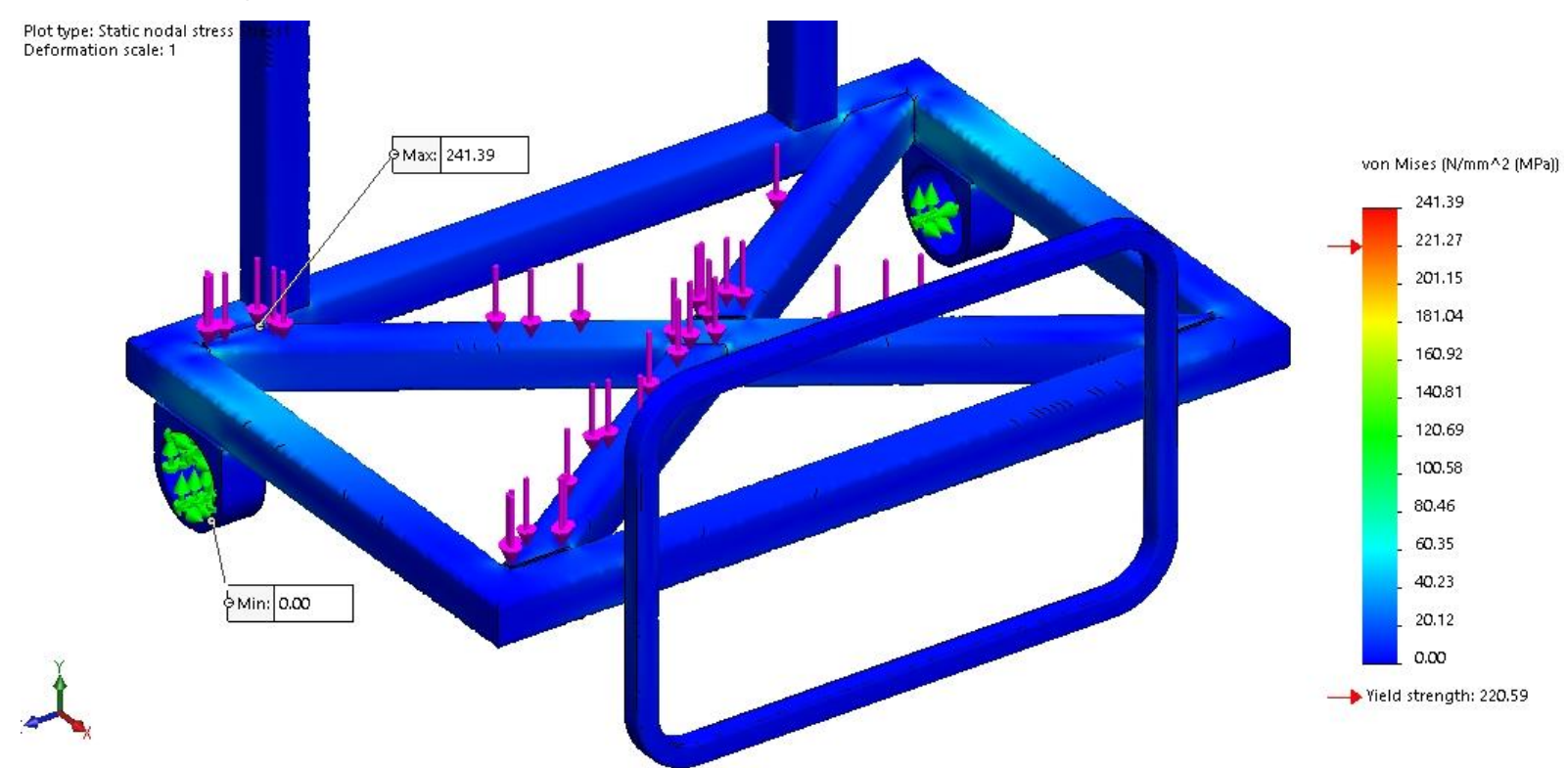

Fig. 16 Von-Mises stress distribution under $3200 \mathrm{~N}$ static load

The advantage of determining Von-Mises stress that is can calculate nodal point stress and the zone where failure occurs can be detected easily when it crosses the value of Yield stress. In figure 16 the area of max stress has been shown. In this way, the most vulnerable or safe zones of the frame can be detected easily. 


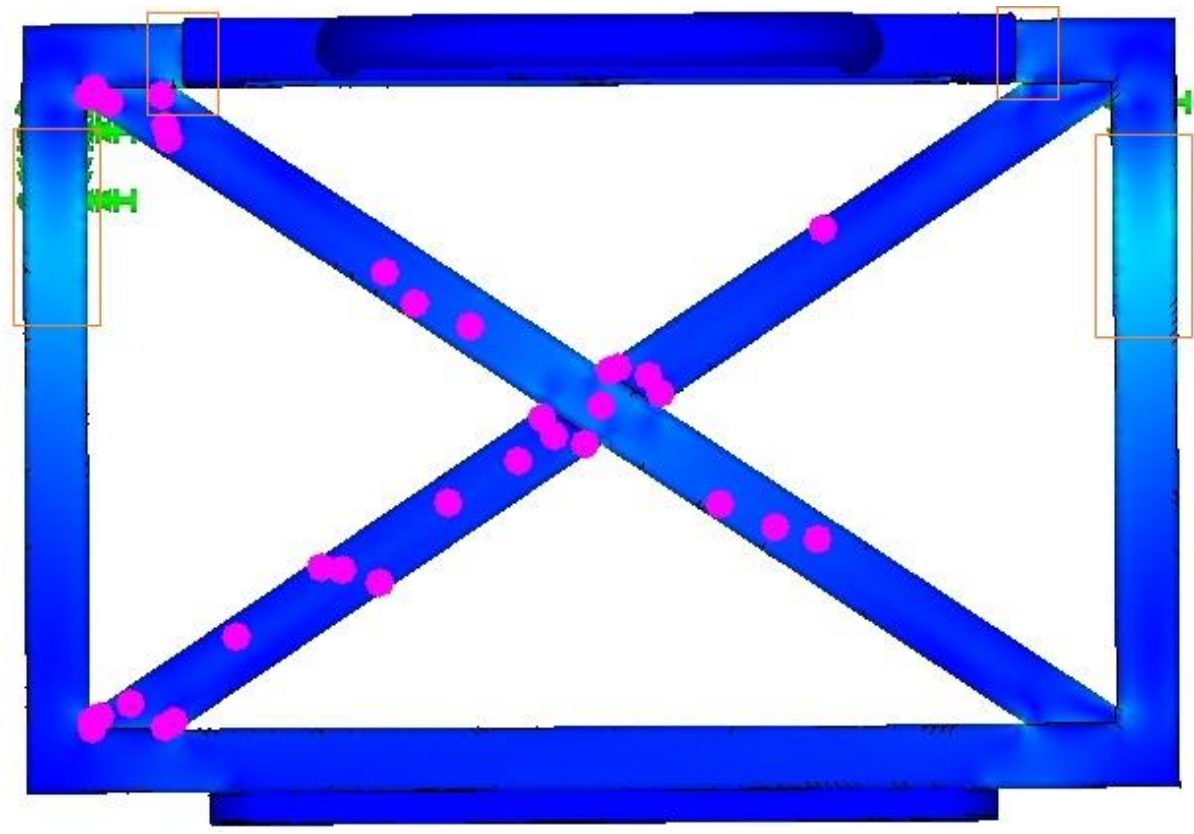

Fig. 17 Most affected zones under loads marked in red

The nodal stresses on different faces are illustrated in the order of the faces.
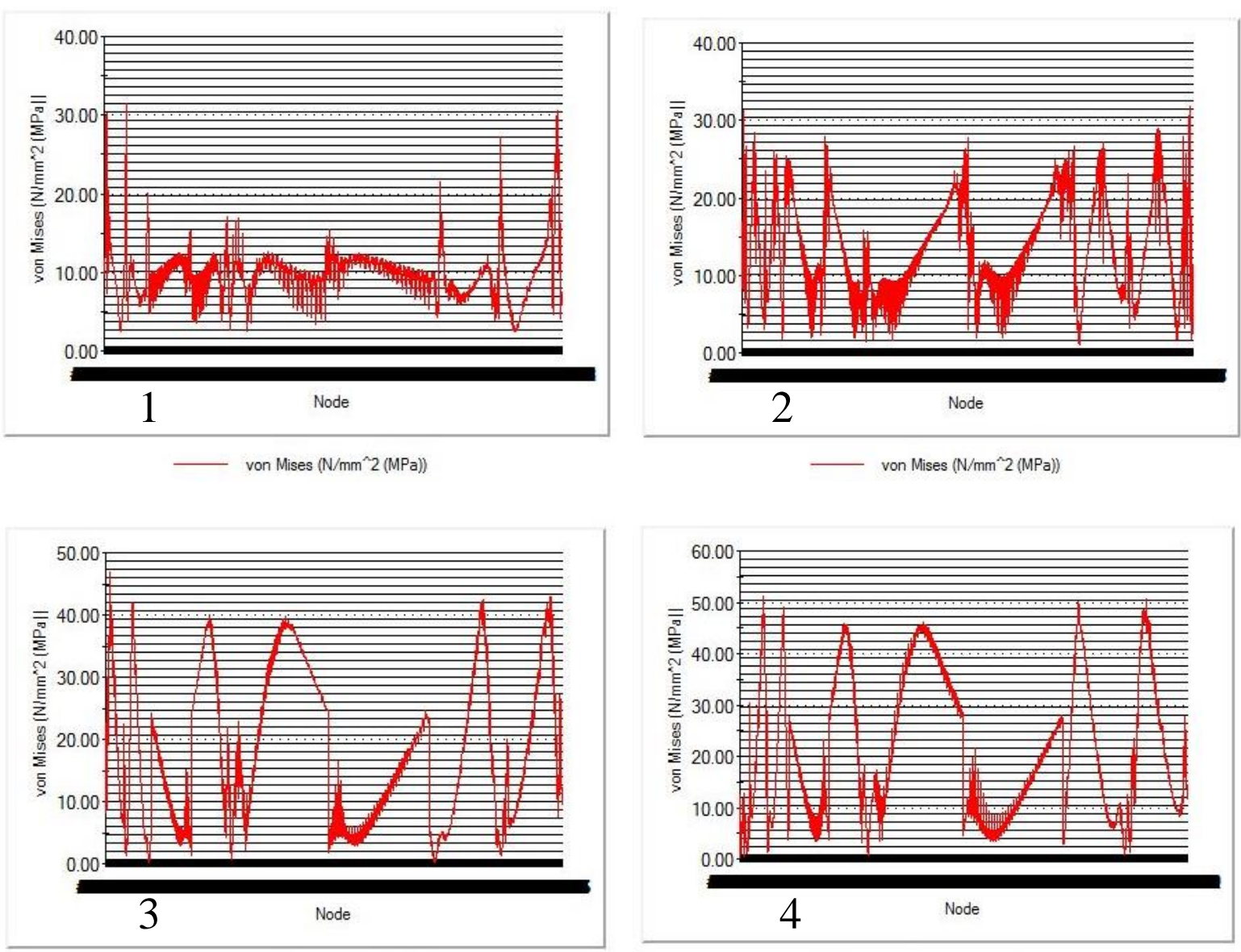

von Mises (N/mm^2(MPa))

— von Mises (N/mm² (MPa)) 

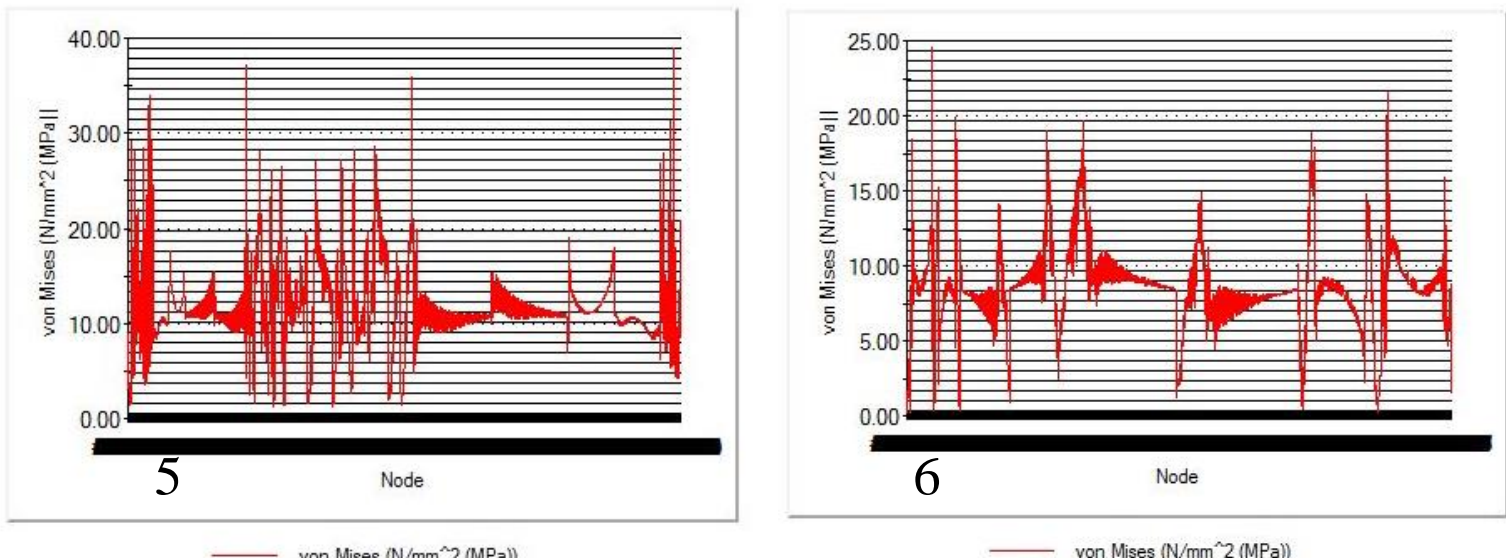

Fig. 18 Nodal Von-Mises stress on faces in order (1-6).

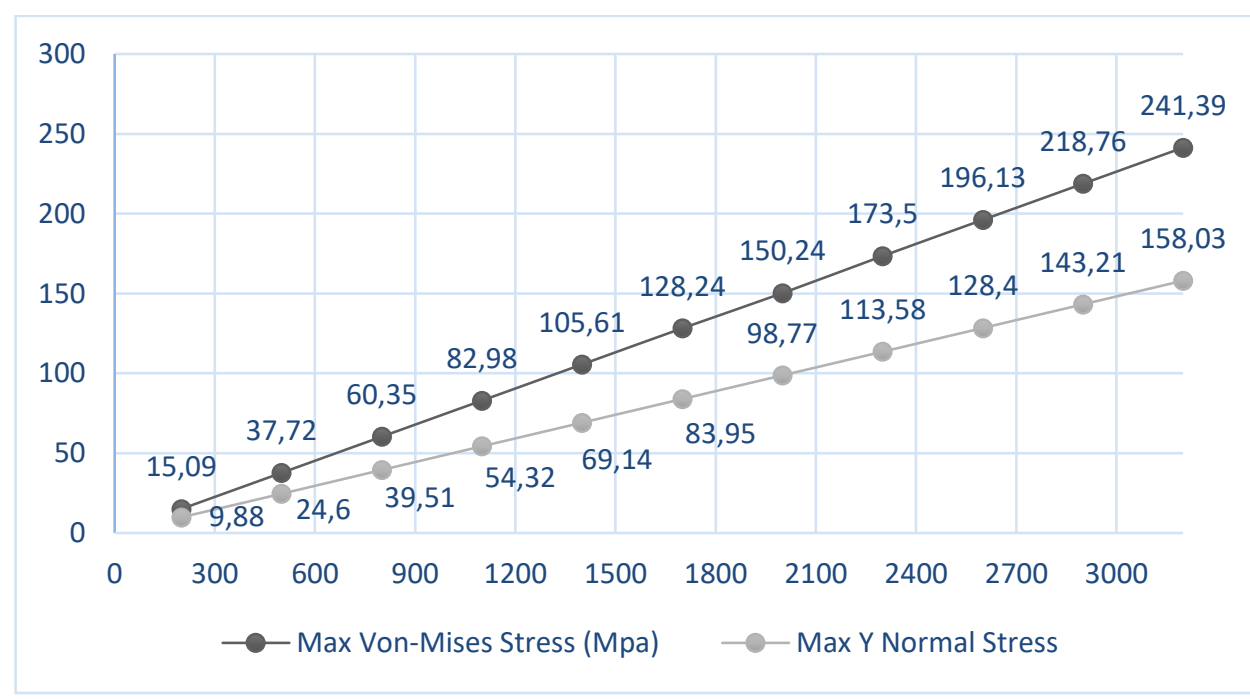

Fig. 19 Maximum Von-Mises and Y Normal stress under different loads

From the figure-20, the safety factor for safe loading has been found as 1.0044 which means that around $1900 \mathrm{~N}$ loads can be stored in static condition on the main load-carrying structure.

The safe weight $=1900 / 9.81=193.67 \cong 194 \mathrm{~kg}$

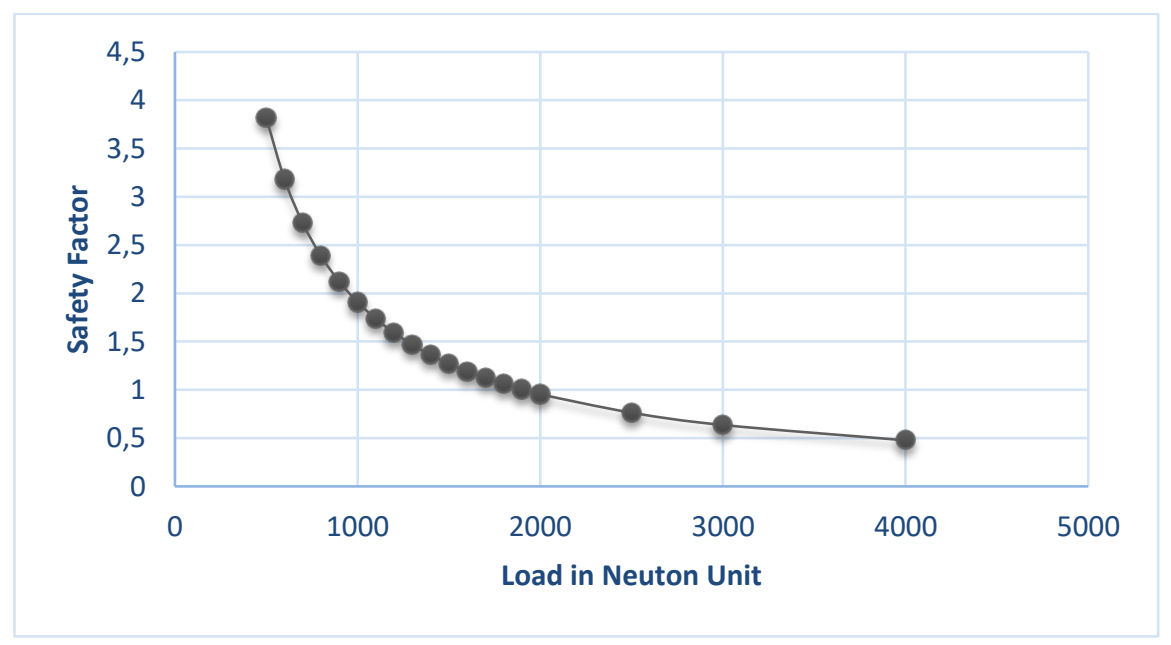

Fig. 20 The factor of safety vs loads plot 
The selected material details, required dimensions \& cost are listed in the below table 1 .

Table 1 The List of Components for the stair climbing cart

\begin{tabular}{ll}
\hline Name of the Component & Quantity \\
\hline 2x2 square pipes & $15 \mathrm{ft}$ \\
1x1 square pipes & $12 \mathrm{ft}$ \\
0.5 in pipe & $8.5 \mathrm{ft}$ \\
Bearings & 2 pieces \\
Machined parts & 2 pieces \\
Phenolic wheel & 8 pieces \\
Nuts \& bolts & 8 pieces \\
\hline
\end{tabular}

\section{CONCLUSION}

In this stair climbing cart design cost, material availability, production process availability, human factors, customer requirements, etc. all factors have been equally considered. The newly added features in this design will eliminate stress on fingers, hands, backbone \& corresponding body parts. The stair climbing mechanism and constraint equation will help to set the dimension of wheels and other parts according to the stair size of any region although there is very little variation. There is a direct relationship between the pulling angle and pulling force. The pulling angle varies according to user height. This design can carry a satisfactory range of load that is determined from the structural analysis. This design is totally unique than others in the pauserest feature which provided the function to keep the cart standing between two stairs by keeping two backward wheels on a stair and another forward wheels on the next stair. In this design, all constraints have been satisfied \& also the strength, durability \& longevity of the structure have been increased which has been tested in the structural simulation. Carrying heavy loads over stairs may cause injuries to a human being such as back pain. This stair climbing cart definitely eliminates human effort to carry goods. This research will help the interested manufacturers who want to commercially produce it for mass customers because all required design analysis, possible dimension adjustment equations, list of components \& QFD have been added here.

\section{ACKNOWLEDGEMENT}

The authors want to thank Md. Asadujjaman (Assistant Professor, Department of Industrial \& Production Engineering; Rajshahi University of Engineering \& Technology), Md. Zahidul Islam and Md. Sazol Ahmmed (Lecturer, Department of Industrial \& Production Engineering; Rajshahi University of Engineering \& Technology) for their direction and co-operation. Also, the authors want to thank Avijit Mallik and Md. Arman Arefin (Department of Mechanical Engineering; Rajshahi University \& Technology) for his co-operation in the mechanics analysis section. 


\section{REFERENCES}

[1] Barney, Jay B. "Strategic Factor Markets: Expectations, Luck, and Business Strategy." Management Science 32 (10), INFORMS , pp. 1231 - 1241, 1986. DOI: $10.1287 / \mathrm{mnsc} .32 .10 .1231$

[2] karl T. Ulrich; Steven D. Eppinger. Product Design and Development. Tata McGraw-Hill Education, 2003.

[3] Woodson, Wesley E., et al. Human Factors Design Handbook: Information and Guidelines for the Design of Systems, Facilities, Equipment, and Products for Human Use. McGraw-Hill, 1992. https://trid.trb.org/view/357534

[4] Charles J. Fouchey, Jr. "Stair Climbing Cart”, U.S. Patent No. 4,264,082, Mar. 1981, https://patents.google.com/patent/US4264082A/en

[5] John F Fleming. "Stair-Climbing Vehicle", U.S. Patent No. 3,450,219, Mar. 1969, https://patents.google.com/patent/US3450219A/en

[6] Eshcol Silas Gross. "Power-Operated Dolly", U.S. Patent No. 3,698,501, June 1972, https://patents.google.com/patent/US3698501A/en

[7] Chiun J. Cheng. "Stairway Accessible Carry Cart with Foldaway Wheels", U.S. Patent No. 4,858,940, Mar. 1989, https://patents.google.com/patent/US4858940A/en

[8] Robert H. Shaffer. "Collapsible Utility Cart”, U.S. Patent No. 4,047,724, Mar. 1977, https://patents.google.com/patent/US4047724A/en

[9] Henry Diener. "Manual Utility Cart", U.S. Patent No. 4,531,752, Dec. 1985, https://patents.google.com/patent/US4531752A/en

[10] Roman Andruchiw. "Stair Climbing Device", U.S. Patent No. 4,109,740, June 1978, https://patents.google.com/patent/US4109740A/en

[11] Ed Carlile. "Collapsible Cart Assembly", U.S. Patent No. 4,865,346, Nov. 1989, https://patents.google.com/patent/US4865346A/en

[12] Chenette Edmond Zenan; Joseph C Chenette. "Endless Tread Stair Climbing Truck", June 1952, https://patents.google.com/patent/US2620041A/en

[13] John Grace. "Collapsible and Foldable Cart Having a Stabilization Member", U.S. Patent No. 5,626,352, Aug. 1997, https://patents.google.com/patent/US5626352A/en

[14] Eugene A. Kazmark, Jr. “Collapsible Cart”, U.S. Patent No. 5,941,543, Mar. 1999, https://patents.google.com/patent/US5941543A/en

[15] William B. Martin. "Stair-Climbing Wheel Utilizing an Involute Curve Configuration", U.S. Patent No. 4,674,757, June 1987, https://patents.google.com/ patent/US4674757A/en

[16] Hans vom Braucke; Manfred vom Braucke. "Two-Wheeled Trolley with Vertical Frame and Foldable Support Wheels", U.S. Patent No. 5,630,601, May 1997, https://patents.google.com/patent/US5630601A/en

[17] Hong, Hee Seung, et al. "Optimal Design of Hand-Carrying Rocker-Bogie Mechanism for Stair Climbing." Journal of Mechanical Science and Technology 27 (1), Korean Society of Mechanical Engineers, pp. 125 - 32, 2013. DOI:10.1007/s12206-012-1212-y

[18] Eshcol Silas Gross. "Power-Operated Dolly", U.S. Patent No. 3,698,501, June 1972, https://patents.google.com/patent/US3698501A/en 
[19] Samuel Wyrick. "Stair Climbing Cart", US 2007/0075509, Oct. 2007, https://patents.google.com/patent/US20070075509A1/en

[20] Zhang, Lin, and Feihong Xi. "An Optimization Design for the Stair-Climbing Wheelchair", 2012, http://www.diva-portal.org/smash/record.jsf?pid= diva2\%3A829385\&dswid=-1397

[21] Ki-Soo Kim. "Driving System for Stair-Climbing Vehicle", US 8,393.420 B2, 2013, https://patents.google.com/patent/US8393420B2/en.

[22] Krys, Václav, et al. "The Synthesis and Testing of a Shaped Wheel for Stairs Climbing Robot.”, Applied Mechanics and Materials 555, Trans Tech Publications, pp. 178 - 85, 2014. DOI: $10.4028 / w w w . s c i e n t i f i c . n e t / A M M .555 .178$

[23] Steve, Rich, et al. "Adjustable Lift Truck”, US 9,139.214 B2, Dec. 2015, https://patents.google.com/patent/US9139214B2/en

[24] Richard Danziger. "Stair Climbing Assistance Device", US 9,133,624 B2, Dec. 2015, https://patents.google.com/patent/US9133624B2/en

[25] Cheng, Ming-chuan. "Stair Climber", US D 808,868 S, Jan. 2018, http://www.freepatentsonline.com/D808868.html

[26] Behera, Pravat Kumar, and Ankur Gupta. "Novel Design of Stair Climbing Wheelchair." Journal of Mechanical Science and Technology 32 (10), Korean Society of Mechanical Engineers, pp. 4903 - 4908, 2018. DOI:10.1007/s12206-018-0938-6

[27] Paška, Z., Fojtík, F., Ferfecki, P. "Full field evaluation of the stress tensor components in 2D photoelasticity via computer software", Strojnícky časopis - Journal of Mechanical Engineering 66 (2), pp. 63 - 66, 2016. DOI: 10.1515/scjme-2016-0019

[28] Hu, Kai, Xiao-qing Gan. "The Manufacturer's Trade-Off between Raw Material Quality and Total Cost - With Hog Supply Chains' Feed Quality Selection Strategy for Example." 2011 International Conference on Management and Service Science, IEEE, pp. 1 - 4, 2011. DOI: $10.1109 / \mathrm{ICMSS} .2011 .5998332$

[29] Hague, R., et al. "Material and Design Considerations for Rapid Manufacturing." International Journal of Production Research 42 (22), Taylor \& Francis Group, pp. 4691 - 4708, 2004. DOI: 10.1080/00207840410001733940

[30] Kong, Yong-Ku, et al. "Comparison of Comfort, Discomfort, and Continuum Ratings of Force Levels and Hand Regions during Gripping Exertions.” Applied Ergonomics 43 (2), Elsevier, pp. 283 - 289, 2012. DOI: 10.1016/J.APERGO.2011.06.003

[31] Saranjam, B., Bakhshandeh, K., Kadivar, M. H. "Dynamic behaviour of a beam with nonuniform linear varying cross-section under moving load", Strojnícky časopis - Journal of Mechanical Engineering 57, pp. 45 - 58, 2006. 